\title{
CORRECTION
}

\section{Correction to: Skeletal Radiology Volume 49, issue 1, January 2020}

The Publisher

Published online: 16 December 2019

(C) ISS 2019

Correction to: Skeletal Radiology Volume 49, issue 1,

January 2020

https://doi.org/10.1007/s00256-019-03244-7

https://doi.org/10.1007/s00256-019-03250-9

https://doi.org/10.1007/s00256-019-03251-8

https://doi.org/10.1007/s00256-019-03255-4

https://doi.org/10.1007/s00256-019-03256-3

https://doi.org/10.1007/s00256-019-03257-2

https://doi.org/10.1007/s00256-019-03258-1

https://doi.org/10.1007/s00256-019-03259-0

https://doi.org/10.1007/s00256-019-03260-7

https://doi.org/10.1007/s00256-019-03261-6

https://doi.org/10.1007/s00256-019-03263-4

https://doi.org/10.1007/s00256-019-03264-3

https://doi.org/10.1007/s00256-019-03265-2

https://doi.org/10.1007/s00256-019-03268-z

https://doi.org/10.1007/s00256-019-03269-y

https://doi.org/10.1007/s00256-019-03275-0

https://doi.org/10.1007//00256-019-03282-1

https://doi.org/10.1007/s00256-019-03313-x

https://doi.org/10.1007/s00256-019-03324-8

https://doi.org/10.1007/s00256-019-03327-5

https://doi.org/10.1007/s00256-019-03332-8

"Unfortunately in Volume 49, Issue 1 had been published online with an incorrect date (2001 instead of 2020).

The publisher regrets this error and the date has been corrected online."

The Publisher

Springer-Verlag GmbH, DE, Heidelberger Platz 3,

14197 Berlin, Germany 